\title{
Artificial intelligence based on agent based modelling with cyber security for remote operated vehicle on dangerous terrain
}

\author{
Priyanka Kumari*, S. T. Aarthy
}

\author{
${ }^{1,2}$ Department of Electronics and Communication Engineering, SRM Institute of Science and Technology, Kattankulathur \\ *Corresponding Author Email: cutepriyanka42@gmail.com
}

\begin{abstract}
A major problem of decision making for autonomous robots is the localization of the robots towards the origin. The point on which the paper is mainly focusing to save human lives, money and conserve the environment too. In the proposed project a firefighter robot is implemented which is efficient to detect fire flame and smoke and cyber security are implemented to secure the data that are recorded in a web page. Here using the RGB to HSV algorithm and motion detection algorithm to detect the fire flame and smoke in python language.
\end{abstract}

Keywords: Motion detection and RGB to HSV algorithm.

\section{Introduction}

Artificial intelligence (AI) is a field of computer science which describes the formation of smart machines that work and react like a human being. Some of the activities of AI are Speech recognition, Learning, Planning, Problem solving and helps us in diminishing the error and the chance of reaching accuracy with a greater degree of precision is a possibility. In the medical field also, we will find the advanced application of AI as identifying and observing of neurological disorders as it can affect the brain activities and radio-surgery.

Human life is more precious for us, removing the effect of fire hazards we proposed this technique. In this paper for fire detection using image processing technique to segmented the fire flame from the image frame, which is getting from the video. Our proposed algorithm is RGB to HSV and also we find out the motion and shape changing in fire using motion detection algorithm. After that, we compare the result getting from the algorithm and the result from the IR sensor.

In industry, oil, poisonous gases, and many other inflammable materials are used for production and other industrial purposes, Under such conditions, the chance of fire accidents are more. Different fuels create different types and color of fires and according to that fire is divided into different classes. Different class of fire requires different types of fire extinguishing agents. Nowadays cybersecurity takes the important role in robotics. Cybersecurity can be a useful term but tends to ignore exact definition. Cyber security protects the data and integrity of computing valuable data belonging to or connecting to an organizations network. It has the purpose to defend those valuable data against all threat actors. Ensuring cybersecurity requires coordinated achievements throughout an information system. Elements of cybersecurity are including application security, Information security, Network security, Disaster recovery/business continuity planning, Operational security, End-user education. We are going to use the encryption method. In this method, converting a plain text message into ciphertext which can be decoded back into the original message. An encryption algorithm along with a key is used for the encryption and decryption of data. There are several types of data encryption, which form the basis of network security are DES/3DES or TripleDES (Data Encryption Standard algorithm), Blowfish, AES, Twofish, IDEA, MD5, SHA 1, HMAC, algorithm etc. Here we are using the python language, it is easy for beginner if they know programming language.

Python is an analysed high-level programming language for general-purpose programming and code readability much easier than any other programming language. Complexity of code is decreases and code size is also reduces.

Table 1.1: Concept of fire

\begin{tabular}{|c|c|l|}
\hline $\begin{array}{c}\text { Types of } \\
\text { fire }\end{array}$ & Fire Extinguishers & \multicolumn{1}{|c|}{ Example } \\
\hline Class A & $\begin{array}{c}\text { Water and Foam, Dry } \\
\text { chemical, clean agent, } \\
\text { water mist }\end{array}$ & $\begin{array}{l}\text { fires in ordinary combustibles such as } \\
\text { wood, paper, cloth, rash, and plastics }\end{array}$ \\
\hline Class B & $\begin{array}{c}\text { Carbon Dioxide, Dry } \\
\text { Chemical, Clean } \\
\text { Agent }\end{array}$ & $\begin{array}{l}\text { flammable liquids such as gasoline, } \\
\text { petroleum oil, paint and also } \\
\text { flammable gases such as propane and } \\
\text { butane. }\end{array}$ \\
\hline Class C & $\begin{array}{c}\text { Carbon Dioxide, Dry } \\
\text { Chemical, Clean } \\
\text { Agent, Water Mist }\end{array}$ & $\begin{array}{l}\text { Energizedelectrical equipment such as } \\
\text { the motor, transformer, and } \\
\text { appliances. }\end{array}$ \\
\hline Class D & Dry Powder & $\begin{array}{l}\text { combustible metals such as potassium, } \\
\text { sodium, aluminum, and magnesium. }\end{array}$ \\
\hline Class K & Wet Chemical & $\begin{array}{l}\text { cooking oils and greases such as } \\
\text { animals fats and vegetable fats. }\end{array}$ \\
\hline
\end{tabular}

\section{Literature Survey}

H.B. WU shows that the firefighting robot detect the fire through monocular camera. They used full-closed loop control video detection algorithm, from that they realize real-time flame detection. They also used the optical sensor to remove the effect of sunlight on fire image. So, it is easily used in open area also. Location algorithm for fire flame and image recognition of the water jet is used to find out the center of the fire. If we use extinguisher at the center of the fire, that is more effective. The drawback of this project is that it can't locate and extinguish the fire appropriately due to monocular vision configuration. It is only applicable on the ground. [6] 
Chinmaya Kaundaya shows that an intelligent Surveillance System using Raspberry $\mathrm{Pi}$ and image processing technique. In which, they are using LBP algorithm to the face and PIR sensor to detect the motion, at any time someone comes within the range. Here they are using python language with OpenCV. OpenCV is a library, which is mainly use for real-time computer vision application. LBP algorithm is used for mainly classification and feature extraction in computer vision. Here at first PIR sensor works to detect the motion, the camera take the picture and send it to the owner. It is efficient and low maintenance cost but more energy consumption due to system is continuously ON. [4]

Dr.j. Subhash Chandra bose shows that the fire and gas detection through the sensors and cybersecurity for the Robot. Here, they used MAPLAB IDE, Proteus VSM, Android studio and APK SDK AVR studio software. Here in robot, they ensure security and privacy guarantees using cybersecurity. This project is more effective if we use image processing technique to detect the fire flame instead of sensors because sensors becomes more sensitive in open environment. [5]

Topias jarvinena demonstrates that the gadget uses a well-established Arduino Microcontroller and additionally a Raspberry Pi single board computer. The performance is achieved with $\mathrm{C}$ and Python programming languages. The operability is approved toward framework Execution assessment in the mixture for air and hydrogen gas, using both commercial and experimental Taguchi type metal oxide semiconductor sensors. The experimental sensors are bogus by inkjet printing platinum decorated tungsten oxide nanoparticles onto an electrode arrangement on a silicon substrate which is then wire bonded to a chip carrier. [10]

Jan Kristanto wibisono demonstrates that how to merge the depth and color detail to enhance the advance color image segmentation techniques. They accept some extent arrangements, integrate their outputs to yields the ultimate results and escapade the consistent data to enhance the color segmentation. This research is to integrate color and depth message to develop an acceptable image segmentation. [7] Chaohui $\mathrm{Lu}$ shows that implementation of a system about applying ant colony algorithm to image segmentation, which is based on the aspects of the discreteness of digital image and the fuzzy clustering ability of ant colony algorithm. There are mainly three contents in the algorithm. The first part is to extract the features of an image including the RGB values, the gradient, and the neighborhood. The second part is to set the clustering center with the method of a combination of statistics and artificial selection. And the third part is to apply the ant colony algorithm to segment a color image. [3]

\section{Proposed Design}

In order to perform run-time operations, a camera is used. Which is connected to the raspberry pi 3 , it is the second-generation Raspberry Pi. It has enhanced Quad-Core Processor and 1GB RAM. In this, we build our own workstation to create and manage our documents and spreadsheets with ease using python with OpenCV. Here the camera is connected to the CSI port in raspberry pi 3 and also connect the IR sensor and Propane Methane Gas Sensor to raspberry pi 3. We use HDMI port to connect the raspberry pi 3 to remote through Wi-Fi and also send the encrypted in a web page.

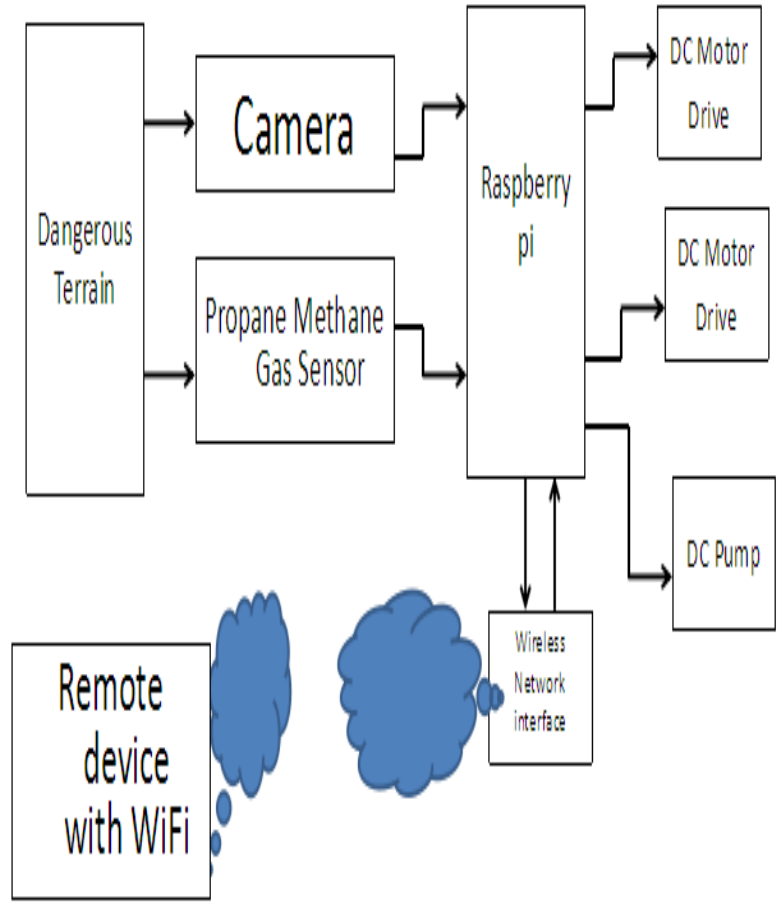

Fig 3.1: Fire Detection mode

In the proposed paper first, take each frame of the video and Convert each frame from BGR to HSV color-space to find the specific color after that set up the threshold to the HSV image for a range of specific color. After that take decision according to the IR sensor output and motion detection algorithm output, we apply the fire extinguisher according to the class of fire. Here, we are using the water pump and carbon dioxide as a fire extinguisher.

\section{Proposed Algorithm}

\section{A. RGB to HSV algorithm}

Color vision can be performed using Red, Green, Blue (RGB), Hue, Saturation, Value (HSV), Hue, Saturation, Lightness (HSL), Lab, YUV, etc. Color spaces. A color space is a technique by which we can enumerate, produce and imagine color. A huge difference between human and computer of understanding the color space. We may define a color by its aspects of brightness, hue, and colorfulness but a computer may specify a color using the amounts of red, green and blue phosphor emission required to meet the exact color. RGB color space illustrates colors in terms of the amount of red, green, and blue present and in HSV color space illustrates colors in terms of the Hue, Saturation, and Value. In situations where color representation plays an integral role, the HSV color model is getting more preferences over the RGB model. The HSV model describes colors similarly to how the human eye tends to distinguish color. RGB defines color in terms of a integration of primary colors. Whereas, HSV describes the color by comparisons such as color, vibrancy, and brightness. In OpenCV to load an image, the color information is saved in the order of Blue, Green, Red (BGR) instead of RGB. For BGR all the value of blue, green and red lies between $0-255$ but in HSV, H(Hue) lies between 0 to 360 and $\mathrm{S}$ (saturation) and $\mathrm{V}$ (value) lies between $0 \%$ to $100 \%$. Here we have to select the threshold value, according to that if the pixel value is greater than the threshold value then it may assign value of white color and else value of black color.

$\operatorname{dst}(x ; y)=\left\{\begin{array}{l}\max \text { Value }, \operatorname{src}(x ; y)>\text { thresh } \\ 0, \text { otherwise }\end{array}\right.$ 


\section{B. Motion detection algorithm}

The proposed algorithm, the motion, and shape of the fire will be detected. At first, we separated the video into several image shots(frames), then use RGB to HSV algorithm. We get the result, then we make the first frame as a background image and subtract the current image from the background image. If the pixel difference is greater than the threshold value then shows that movement is present in pixel(image) otherwise make it background image. After that to remove the noise from the image we use erosion method. Due to erosion method, the image will be compressed and detach the two connected objects. After that, get a noise-free image, then we will do dilation to that image and joining broken parts of an object. According to this algorithm, we can predict or learn that the fire is having or not. For that compare the output of the IR(Infrared radiation) sensors and the output whose getting from the raspberry pi 3by images(camera). If the condition is satisfied then finally consider that the fire is detected through Robot. After that, we apply the extinguisher according to the class of fires.

\section{Result}

At first, take a frame of pixels from the video, then saved the image as a background image and using HSV algorithm we got a masked image. To removing the noise from the masked or grayscale image we are doing erosion morphology, then got the erosed image. To join the breaking object in an image we do dilation morphology, then got dilated image, then dilated image is subtracted from the background image frame. If the value of the pixel is greater than the threshold value then it tells the motion is there otherwise the final result fed to the background image frame. Here we take two frames from two different videos. After the simulation we got the fire is detected in image 1 and no fire for image 2 on the basis of motion algorithm.

\section{Image 1}

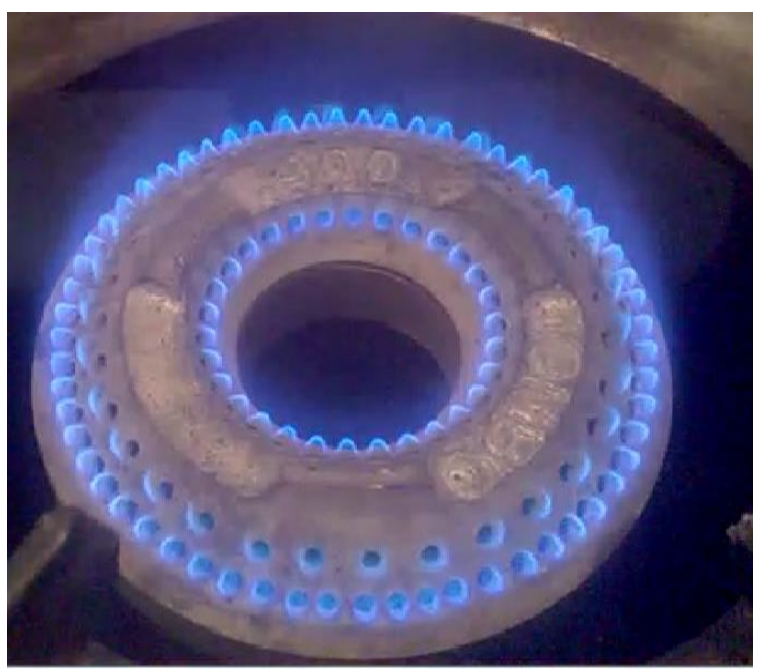

Fig 4.1 (a): Original image(shot)

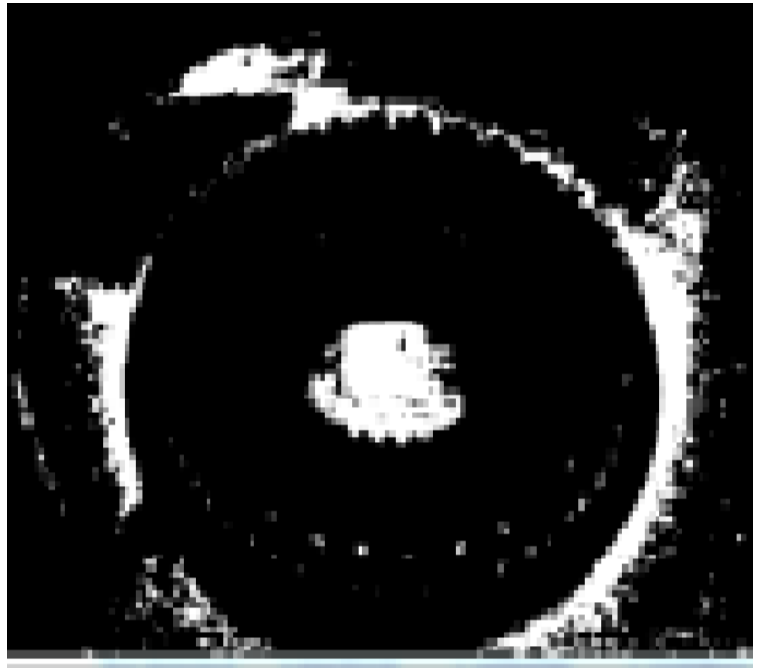

Fig 4.1(b): Masked image

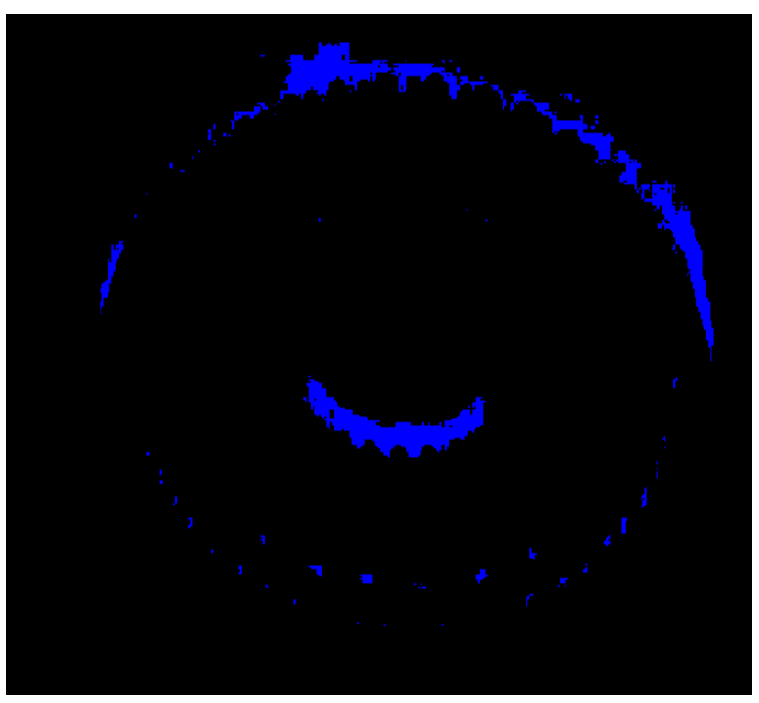

Fig 4.1(c): Final image (result)

Image 2

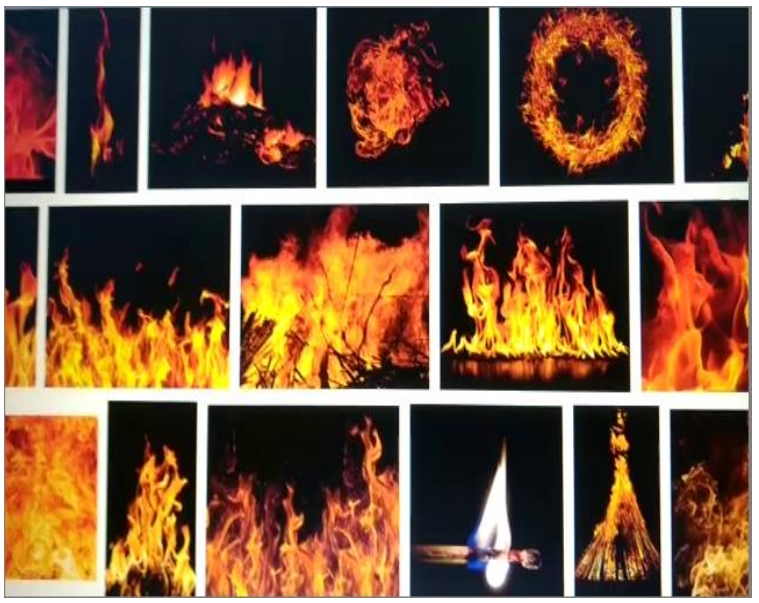

Fig 4.2 (a): Original image 


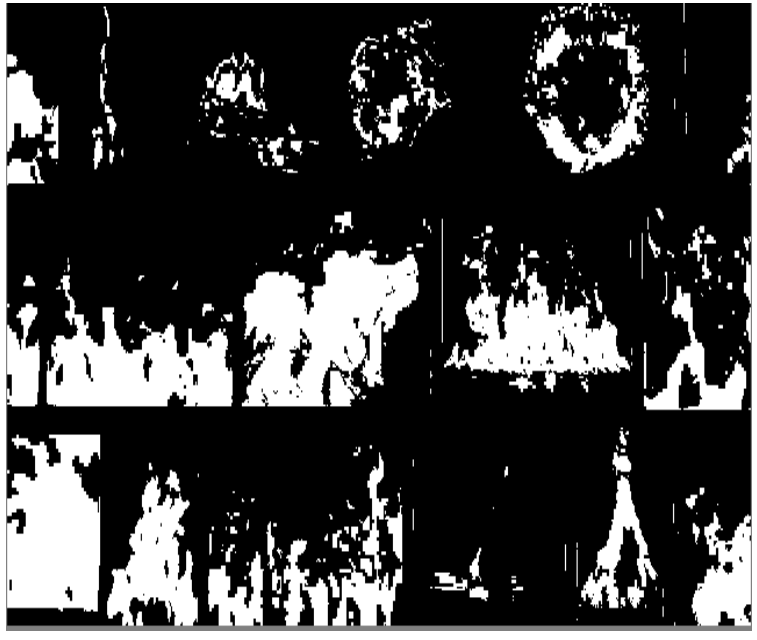

Fig 4.2(b): Masked image

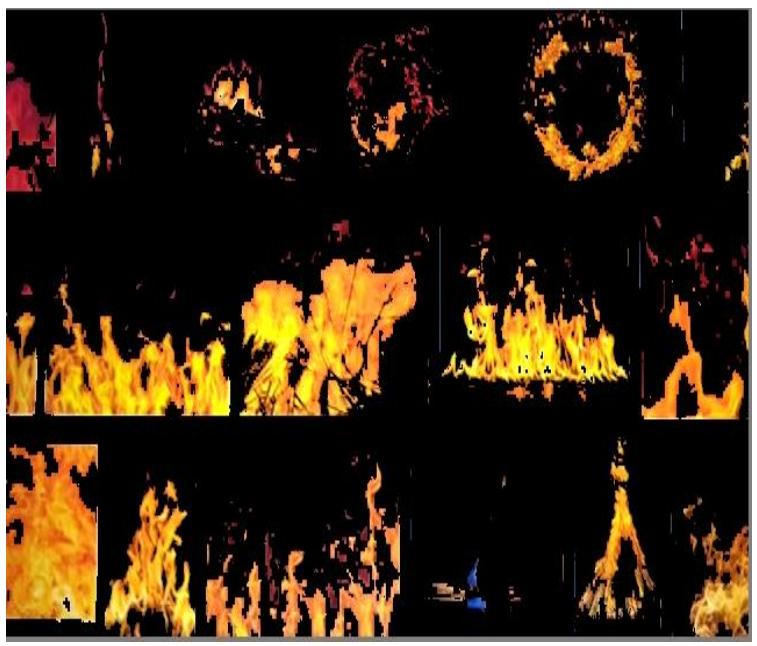

Fig 4.2 (c): Final image (result)

We have taken a video which contains many shots, from that we have taken 25 shots for observation. we are using RGB to HSV algorithm and motion detection algorithm and have got the output. Then compare the IR sensor output to algorithm output and get final result. According to observation table, we compare the the actual output to the final output and got the efficiency of fire detection is $92 \%$.

\section{Conclusion}

In this paper, RGB to HSV algorithm and motion detection algorithm are used to detect the fire flame and smoke. Due to the use of a combination of algorithms, it gives better results in terms of accuracy and time. Using motion detection algorithm and IR sensor output we are able to differentiate the normal color image from real-time fire image. The main concept of this paper is to save human lives, money and conserve the environment too. The proposed project can also be used for general purpose applications like home security, in companies, etc.
Table 4.1: Observation of fire detection

\begin{tabular}{|c|c|c|c|c|c|}
\hline $\begin{array}{l}\text { Obs. } \\
\text { no. }\end{array}$ & $\begin{array}{l}\text { Motion } \\
\text { algorithm } \\
\text { output }\end{array}$ & $\begin{array}{l}\text { IR sensor } \\
\text { output }\end{array}$ & $\begin{array}{l}\text { Final } \\
\text { output }\end{array}$ & $\begin{array}{l}\text { Actual } \\
\text { output }\end{array}$ & $\begin{array}{l}\text { Obs } \\
\text { outpu }\end{array}$ \\
\hline 1 & High & High & $\begin{array}{l}\text { Fire } \\
\text { detect }\end{array}$ & $\begin{array}{l}\text { Fire } \\
\text { detect }\end{array}$ & True \\
\hline 2 & High & High & $\begin{array}{l}\text { Fire } \\
\text { detect }\end{array}$ & $\begin{array}{l}\text { Fire } \\
\text { detect }\end{array}$ & True \\
\hline 3 & High & High & $\begin{array}{l}\text { Fire } \\
\text { detect }\end{array}$ & $\begin{array}{l}\text { No Fire } \\
\text { detect }\end{array}$ & False \\
\hline 4 & High & Low & $\begin{array}{l}\text { No Fire } \\
\text { detect }\end{array}$ & $\begin{array}{l}\text { No Fire } \\
\text { detect }\end{array}$ & True \\
\hline 5 & Low & Low & $\begin{array}{l}\text { No Fire } \\
\text { detect }\end{array}$ & $\begin{array}{l}\text { No Fire } \\
\text { detect }\end{array}$ & True \\
\hline 6 & Low & High & $\begin{array}{l}\text { No Fire } \\
\text { detect }\end{array}$ & $\begin{array}{l}\text { No Fire } \\
\text { detect }\end{array}$ & True \\
\hline 7 & High & Low & $\begin{array}{l}\text { No Fire } \\
\text { detect }\end{array}$ & $\begin{array}{l}\text { Fire } \\
\text { detect }\end{array}$ & False \\
\hline 8 & Low & High & $\begin{array}{l}\text { No Fire } \\
\text { detect }\end{array}$ & $\begin{array}{l}\text { No Fire } \\
\text { detect }\end{array}$ & True \\
\hline 9 & High & High & $\begin{array}{l}\text { Fire } \\
\text { detect }\end{array}$ & $\begin{array}{l}\text { Fire } \\
\text { detect }\end{array}$ & True \\
\hline 10 & High & High & $\begin{array}{l}\text { Fire } \\
\text { detect }\end{array}$ & $\begin{array}{l}\text { Fire } \\
\text { detect }\end{array}$ & True \\
\hline 11 & Low & High & $\begin{array}{l}\text { No Fire } \\
\text { detect }\end{array}$ & $\begin{array}{l}\text { No Fire } \\
\text { detect }\end{array}$ & True \\
\hline 12 & Low & Low & $\begin{array}{l}\text { No Fire } \\
\text { detect }\end{array}$ & $\begin{array}{l}\text { No Fire } \\
\text { detect }\end{array}$ & True \\
\hline 13 & Low & Low & $\begin{array}{l}\text { No Fire } \\
\text { detect }\end{array}$ & $\begin{array}{l}\text { No Fire } \\
\text { detect }\end{array}$ & True \\
\hline 14 & Low & Low & $\begin{array}{l}\text { No Fire } \\
\text { detect }\end{array}$ & $\begin{array}{l}\text { No Fire } \\
\text { detect }\end{array}$ & True \\
\hline 15 & High & Low & $\begin{array}{l}\text { No Fire } \\
\text { detect }\end{array}$ & $\begin{array}{l}\text { No Fire } \\
\text { detect }\end{array}$ & True \\
\hline 16 & High & High & $\begin{array}{l}\text { Fire } \\
\text { detect }\end{array}$ & $\begin{array}{l}\text { Fire } \\
\text { detect }\end{array}$ & True \\
\hline 17 & High & Low & $\begin{array}{l}\text { No Fire } \\
\text { detect }\end{array}$ & $\begin{array}{l}\text { No Fire } \\
\text { detect }\end{array}$ & True \\
\hline 18 & Low & Low & $\begin{array}{l}\text { No Fire } \\
\text { detect }\end{array}$ & $\begin{array}{l}\text { No Fire } \\
\text { detect }\end{array}$ & True \\
\hline 19 & Low & Low & $\begin{array}{l}\text { No Fire } \\
\text { detect }\end{array}$ & $\begin{array}{l}\text { No Fire } \\
\text { detect }\end{array}$ & True \\
\hline 20 & Low & High & $\begin{array}{l}\text { No Fire } \\
\text { detect }\end{array}$ & $\begin{array}{l}\text { No Fire } \\
\text { detect }\end{array}$ & True \\
\hline 21 & High & High & $\begin{array}{l}\text { Fire } \\
\text { detect }\end{array}$ & $\begin{array}{l}\text { Fire } \\
\text { detect }\end{array}$ & True \\
\hline 22 & High & High & $\begin{array}{l}\text { Fire } \\
\text { detect }\end{array}$ & $\begin{array}{l}\text { Fire } \\
\text { detect }\end{array}$ & True \\
\hline 23 & High & Low & $\begin{array}{l}\text { No Fire } \\
\text { detect }\end{array}$ & $\begin{array}{l}\text { No Fire } \\
\text { detect }\end{array}$ & True \\
\hline 24 & Low & Low & $\begin{array}{l}\text { No Fire } \\
\text { detect }\end{array}$ & $\begin{array}{l}\text { No Fire } \\
\text { detect }\end{array}$ & True \\
\hline 25 & Low & High & $\begin{array}{l}\text { No Fire } \\
\text { detect }\end{array}$ & $\begin{array}{l}\text { No Fire } \\
\text { detect }\end{array}$ & True \\
\hline
\end{tabular}

\section{References}

[1] Angel Manuel Guerrero-Higueras, Noemi DeCastro-Garcia, Francisco Javier Rodriguez-Lera, Vicente Matellan. "Empirical analysis of cyber-attacks to an indoor real time localization system for autonomous robots."Computers \& Security, 2017.

[2] Bonabeau, Eric. "Agent-based modeling: Methods and techniques for simulating human systems."Proceedings of National Academy of Sciences of the United States of America, 2002.

[3] Chaohui Lü, Xingyun Yang and Sha Qi. "Color Image Segmentation Based on the Ant Colony Algorithm."International Congress on Image and Signal Processing, 2015.

[4] Chinmaya Kaundaya, Omkar Pathak, Akash Nalawade, Sanke Parode. "Smart Surveillance System using Raspberry pi and Face Recognition."IJARCCE, 2017.

[5] Dr.j. Subhash Chandra bose, Dr.Marzougui Mehrez, Dr. ahmed Said Badaway, Dr. wade ghribiMr. Harun Bangali, Mr.Asif Basha. "Development and designing of fire fighter robotics using cyber security."IEEE Conference Paper. 2017. 
[6] H.B. WU, Z.J. LI, J.H. YE, S.C. MA, J.W. LI, X.N. Yang. "Firefighting robot with video full-closed loop control."International Journal of Safety and Security Engineering, Vol. 6 (International Journal of Safety and Security Engineering, Vol. 6), 2016.

[7] Hang, Jan Kristanto Wibisono and Hsueh-Ming. "Fusion of Color and Depth Information for Image Segmentation."IEEE international conference paper. 2017.

[8] Kim, DongKeun. "Color Detection using Color Feature Clustering."International conference IP, Computer Vision, and Pattern Recognition. 2017.

[9] L.Su., Kou. "Automatic fire detection system using adaptive fusion algorithm for fire fighting robot."IEEE international conference on system man and cybernatics. 2006.

[10] Topias Järvinena, Gabriela Simone Loritea, Anne-Riikka Rautioa,Koppany Levente Juhászb, Ákos Kukoveczb, Zoltán Kónyab, Krisztian Kordasa,Geza Totha. "Portable cyber-physical system for indoor and outdoor gas sensing."Sensors and Actuators B: Chemical, 2017.

[11] Yun Shang, Zunshui Cheng, Yourning Xin. "\{Fire extingushing model by robots of artificial intelligence based on ABM."IEEE 29th Chinese control and decision conference. 2017.

[12] S.V.Manikanthan and K.srividhya "An Android based secure access control using ARM and cloud computing", Published in: Electronics and Communication Systems (ICECS), 2015 2nd International Conference on 26-27 Feb. 2015, Publisher:IEEE,DOI:10.1109/ECS.2015.7124833.

[13] T. Padmapriya and V. Saminadan, "Inter-cell Load Balancing technique for multi-class traffic in MIMO-LTE-A Networks", International Journal of Electrical, Electronics and Data Communication (IJEEDC), ISSN: 2320- 2084, vol.3, no.8, pp. 22-26, Aug 2015. 